\title{
The Three Positions for Interorganizational Interventionist Researcher: Navigating in the Supplier-Customer Dyad
}

\author{
Vesa Tiitola, Jouni Lyly-Yrjänäinen and Teemu Laine \\ Cost Management Center (CMC), Tampere University, Finland \\ vesa.tiitola@tuni.fi \\ jouni.lyly-yrianainen@tuni.fi \\ teemu.laine@tuni.fi \\ DOI: 10.34190/JBRM.18.2.004
}

\begin{abstract}
The paper identifies and examines different positions of an interventionist researcher, facilitating value co-creation for new technology in customer-supplier dyads. The paper answers two research questions: (1) "what kind of positions can an interventionist researcher assume in a supplier-customer dyad?" and (2) "what should an interventionist researcher consider when choosing a suitable position for her research design?" The paper reflects upon a longitudinal interventionist case study (2017-2020) focused on facilitating and evaluating the value created by new medicine-dispensing robot technology in home-care in Nordic countries. The researchers conducted interventionist research in 11 supplier-customer dyads, with multiple, evolving positions of the researcher(s). As a result, as a contribution to the existing knowledge about the role of the interventionist researchers, the paper proposes three positions that the interventionist researcher can take in an interorganizational supplier-customer dyad: an auditor, a lawyer or a mediator. The auditor investigates the interface between the supplier and the customer as an outsider. The lawyer position compromises this perceived neutrality (but not independence) for deeper access to empirical data regarding one of the organisations. Thus, the lawyer actively pursues the status of 'one of us' with either the supplier or the customer. The mediator expands the previous positions by trying to achieve a status of 'one of us' in both organisations trying to understand both sides of the same story supporting both the supplier's and customers' activities. Importantly, as an extension to the existing knowledge, the paper argues that not only can an interventionist researcher move between the etic and emic domains, but she can also move within the suppliercustomer dyad under examination. Thus, when conducting research within the customer-supplier dyads (and within similarly complex contexts), the interventionist researcher needs to be aware of the existence of different positions and her actual position to the subject of interventionist study. Indeed, the interventionist researcher may choose her role, or the role may be a result of an evolutionary process. The role is 'given' by the people the interventionist researcher interacts with and, thus, not something the researcher can completely decide by herself. However, the interventionist researcher can pursue a specific role that fits her research agenda and design. In any case, the researcher needs to be honest and transparent regarding the actually taken position to avoid potential methodological pitfalls arising from complex, novel research settings.
\end{abstract}

Keywords: interventionist research (IVR), action research, supplier-customer dyad, positions, value co-creation, interorganizational management accounting

\section{Introduction}

The main benefit of an interventionist research approach is the possibility to gain an in-depth understanding of the practice. Interventionist research (IVR) sees the researcher as an active, intervening participant in the phenomenon under investigation (Jönsson \& Lukka, 2007; Suomala et al., 2014, Lyly-Yrjänäinen et al., 2017). This intervention enables the researcher to acquire the status of: 'one of us' in the organisation under study and, in that way, provides access to rich empirical data. Recently, interventionist (action) research has been called to shed light on the economic dimension of customer value (Wouters \& Kirchberger, 2015), which provides an interesting opportunity for interorganizational management accounting studies. This supplier-customer dyad research setting, however, raises new challenges, especially related to concurrently achieving the status as 'one of us' in two organisations with diverging interests. Therefore, the interventionist researchers will have to decide on how the researchers want to position themselves in this interorganizational setting.

Some interventionist studies have already been done in interorganizational contexts, but mainly from an upstream perspective. Several studies have utilised interventionist research in supplier-customer dyads from the customer's perspective (Kulmala et al., 2000; Kajüter \& Kulmala, 2005; Suomala et al., 2010). Studies focusing on interorganizational management accounting blossomed during the turn of the century (Caglio \& Ditillo, 2008), with open-book accounting as one notable application of interorganizational management accounting (Jakobsen, 2013). Interorganizational management accounting and open-book accounting, in particular, were closely tied to collaborative customer-supplier relationships (Jakobsen, 2013). However, the analyses of customer value differ significantly. Customer value proposition becomes more tangible if measurable in financial ISSN 1477-7029

(C)ACPIL

Reference this paper: Tiitola, V., Lyly-Yrjänäinen, J., and Laine, T., 2020. The Three Positions for Interorganizational Interventionist Researcher: Navigating in the Supplier-Customer Dyad. The Electronic Journal of Business Research Methods, 18(2), pp. 115-128, available online at www.ejbrm.com 
terms (Wouters \& Kirchberger, 2015). When studied through a management accounting lens, the analysis and communication of customer-perceived value in the customer-supplier interface can be seen as an application of interorganizational management accounting (Wouters \& Kirchberger, 2015).

Downstream interorganizational management accounting (i.e. value analysis and communication) is, nonetheless, different. The supplier, to provide and propose value to its customers, needs visibility into the customer's operations, changing the power relationships upside down. The party who needs cost information seldom has negotiation power to 'force' the other. Opening up the process cost information to the supplier enables value-based pricing, not necessarily an ideal situation for the customer (Ellström \& Hoshi, 2017). At the same time, customer value is increasingly co-created (or at least co-defined) in the customer-supplier interface when both the customer and the supplier collaboratively think for new ways to improve the customer's offerings or processes (Grönroos, 2008). Hence, analysing customer value as an intervening, yet third, neutral party seems like an excellent opportunity for an interventionist researcher. In such contexts, the neutral third-party researcher may gain access to sensitive (financial) information. When that happens, and the researcher is not allowed to share this information with the other company, the 'one of us' status may erode to 'one of them' in the minds of the managers in the other organisation. This role, therefore, places the researcher in a battlefield of diverging interests (Suomala et al., 2014); acquiring the status as 'one of us' in one organisation might result in becoming 'one of them' in the other.

The objective of this paper is to provide guidelines for interventionist researchers by theorising on and thus examining the positions of an interventionist researcher in customer-supplier dyads. To do that, the paper answers two research questions: (1) "what kind of positions can an interventionist researcher assume in a supplier-customer dyad?" and (2) "what should an interventionist researcher consider when choosing a suitable position for her research design?" The paper reflects upon a longitudinal, four-year interventionist case study (2017-2020) focused on facilitating and evaluating the value created by new medicine-dispensing robot technology in home-care in Nordic countries. In the study, the researchers were conducting interventions in three areas: (1) helping the supplier and the customer's organisation identify sources of value, (2) supporting the redesign of value-creating processes at the customer's organisation and (3) analysing the impact of the technology-enabled value creation. The researchers conducted interventionist research in 11 supplier-customer dyads. The paper introduces three positions for interorganizational interventionist researcher; the researcher needs to either (1) remain as the third party with limited access to both organisations, (2) select a side with limited access to the other organisation or (3) try to navigate between both sides.

The paper is arranged as follows. The second section reflects on prior literature on interventionist research. The third section demonstrates the methodological approach, followed by the empirical findings of the interventionist case study within the multiple supplier-customer dyads in the fourth section. The fifth section reflects upon the three positions proposed in the paper and present guidelines for researchers interested in conducting interventionist research in an interorganizational setting. The paper ends with a concluding overview of the study and proposes future research opportunities.

\section{Literature review}

\subsection{Interventionist research in different streams of management research}

There are a few empirical interventionist studies in the management accounting literature already. Typically, interventionist research has been conducted with single organisations (Laine et al., 2016; Saukkonen et al., 2018; Stormi et al., 2020), or at the supplier interface, primarily from the customer's perspective (Kulmala et al., 2000; Kajüter \& Kulmala, 2005; Suomala et al., 2010). Additionally, interventionist cases have been reported within the methodological studies on interventionist management accounting research (Suomala et al., 2014; LylyYrjänäinen et al., 2017), thus extending the empirical basis for the stream. In this vein, further extending the interventionist research stream, a similar intervention-based research approach has recently been rising in the operations research context (Oliva, 2019; Chandrasekaran et al., 2020). This stream has, however, been mainly focusing on the intraorganizational operations management contexts.

In all the interventionist studies we found on interorganizational management accounting, the intervening researchers were somehow focusing on the suppliers' processes providing cost behaviour logic to support customer's decision-making following the principles of open-book accounting (Romano \& Formentini, 2012). The aim has been for a researcher to be a third, neutral party providing 'impartial' cost analyses shared with the 
customers for well-grounded decisions in a collaborative context to identify win-win scenarios (Kulmala et al., 2000). In some cases, the customer has, at least implicitly, used its negotiation power for the supplier to 'happily' open the books (Suomala et al., 2010). Even in such cases intervening researchers have attempted to position themselves as neutral, third party intermediate, helping the practitioners with some of the interorganizational tasks (Seal et al., 1999). However, the different opportunities in positioning in interorganizational suppliercustomer dyads have mainly been left unexplored.

\subsection{Interventionist research and achieving the status of 'one of us'}

Interventionist research is a form of case study in which the researcher as an active, intervening participant in the phenomena under the investigation (Jönsson \& Lukka, 2007). As pointed out by Jönsson and Lukka (2007), in interventionist research, the researcher is immersed with the object of the study, eroding the neutral position of the researcher, which is often seen as a methodological problem. However, in interventionist research, this is translated to a critical strength, helping gain access to interesting empirical data. Interventionist research can be viewed as a field experiment (Jönsson \& Lukka, 2007), though the theory's contribution does not have to be focused on the experiment itself. In some cases, the intervening work in the field brings up issues that provide even more interesting theory contributions than the intervention itself (Suomala \& Lyly-Yrjänäinen, 2011). The key idea of interventionist research is not only to produce constructs for the practitioners but contribute to the theory, too (Jönsson \& Lukka, 2007; Scapens, 2014). To do this, the interventionist researcher will have to balance between the etic (outsider) and emic (insider) perspectives (Jönsson \& Lukka, 2007).

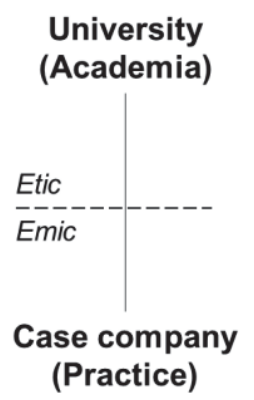

Figure 1: The etic and emic perspective continuum

In the emic perspective, the researcher investigates the phenomena under study as an insider, as typical for interventionist studies (Jönsson \& Lukka, 2007). To make a theoretical contribution, the researcher will have to step back and take an etic, outsider, perspective to "justify the beliefs" and make "the interventionist study comparable to any other research endeavour" (Jönsson \& Lukka, 2007). For a researcher to gain access to an organisation in the first place, she must bring in something such as experience or analytical skills (Jönssön \& Lukka, 2007). At first, the researcher is likely to be treated as an outsider and, in some cases, managers even engage in a type of a child talk when explaining things that they find clear (Jönsson \& Lukka 2007). However, the researcher eventually learns the terminology of the context and starts to speak and behave like the practitioners. This is what is called 'membership work' by Munro (2001). Furthermore, when the researcher works on the intervention, new ideas and information often surface, helping the researcher to earn the respect of experienced practitioners, eventually evolving into a 'one of us' position. At the same time, the researcher needs to see the involvement as part of the membership work, justifying access to the case. Suomala et al. (2014) described this challenge as a battlefield of different (and sometimes even conflicting) interest the interventionist researcher often finds herself in. However, interventionist research in an interorganizational setting introduces even more variables to the battlefield.

One critical feature of interventionist research is understanding the depth of the intervention. Jönsson and Lukka (2007) proposed the concepts of modest and strong intervention. They acknowledge that a researcher 'hmming' at the right (or wrong) place may already impact the course of action in the case organisation, hence - at least theoretically speaking - constituting an intervention. These two categories do not capture the potential ways to intervene in an organisation and, as a result, Suomala and Lyly-Yrjänäinen (2011) proposed the following five levels: (1) intervention through presence, minimal participation in the process, (2) external expert, limited participation, (3) rich participation though within a restricted domain, (4) active and versatile participation, 'almost family' and (5) strong collaboration with the native role as 'one of us'. Again, it is essential to point out 
that the depth of access is defined by the research design and, eventually, the requirements that the empirical data needed for the theory contribution places.

\subsection{Interventionist research in a supplier-customer dyad}

While studies using interventionist research in an interorganizational supplier-customer setting have been made, this kind of setting has not been investigated from the methodological perspective. The supplier-customer dyad introduces an issue regarding the emic perspective that has not received enough attention in the prior literature; can and should the interventionist researcher become an insider in two organisations at the same time? After all, becoming 'one of us' in one organisation might result in the researcher becoming 'one of them' in the other. By expanding the 'practice' (typically an individual case organisation) to a supplier-customer dyad, we transform the previously one dimensional emic and etic continuum (Jönsson \& Lukka, 2007) into a twodimensional triad. Figure 2 illustrates this two-dimensional triad.

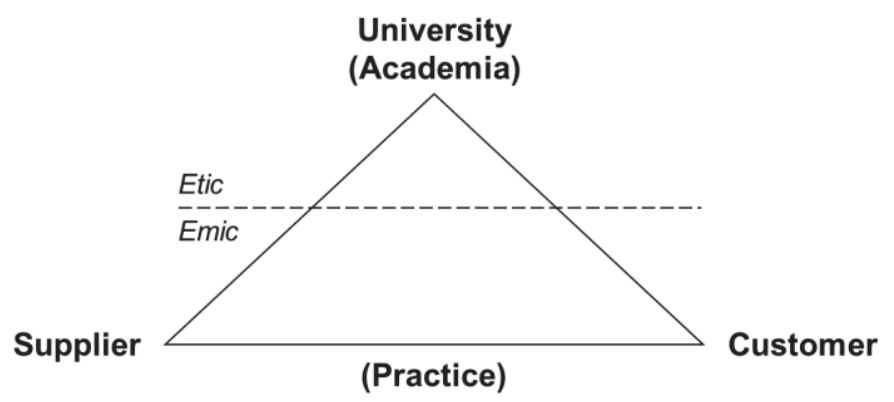

Figure 2: The etic and emic perspective continuum extended into an interorganizational supplier-customer dyad

In this two-dimensional triad, the researcher will have to navigate between (1) remaining as the third party within the etic domain with limited access to both organisations or moving to the emic domain and (2) choosing a side with limited access to the other organisation or (3) trying to navigate between both sides.

\section{Methodology}

The paper analyses the methodological implications of interorganizational interventionist research in suppliercustomer dyads, reflecting upon the analysis of a longitudinal interventionist case study (2017-2020). Methodologically, this is common for many studies on the interventionist research methodology in general (Suomala et al., 2014; Laine et al., 2018; Suomala \& Lyly-Yrjänäinen, 2011). As part of the methodological reflection, we analysed the implications of the nature of our interventions. To do that, we asked ourselves if we were considered as "one of us" in an organisation, and if so, by which party: the supplier, the customer or both. This analysis of the position of the researcher resulted in the identification of the research gap and provided the basis for the methodological contribution of this paper.

The case study investigates supplier-customer dyads with a healthcare technology provider (supplier) and their public home-care customers (customers) in a publicly funded research project. The home-care organisations are commonly publicly funded by the municipalities, and thus, there has to be a financial rationale to justify technology investments. The case technology is a medicine dispensing robot, placed at the home-care patient's (i.e. end customer's) home. It takes the responsibility of reminding and instructing the end customers to take the right medication, as a right dosage, at the right time, highly improving the medicine adherence (Rantanen et al., 2017). Right medicine is ensured by electronic prescriptions that are checked by the pharmacy for drug compatibility. The right dosage is confirmed by the automated dose dispensing (ADD) service provided by the pharmacy where they pack each dosage in sachets according to the individual prescriptions. Finally, the right time is ensured by the robot, that utilises the information on these sachets to coordinate the dosing, ensuring that the end customer uses the sachets according to the intended use. Thus, the robot is provided for medication safety and control, mostly for home-care customers possessing signs of memory disorders or a tendency for drug misuse. To ensure the same level of medication safety, the medication would have to be kept in a locked compartment and the caregivers would have to visit the end customer several times a day. With the robot, the caregivers can free up time from the mechanical medicine distribution work to more social home-care activities. 
The researchers have been actively adapting to the needs of the practice. At first, the researchers were requested to make simple cost calculations, developing the value proposition together with the technology provider. As the technology provider started having more pilot cases, we were requested to document the patient-level (i.e. end customer) impact, firstly, by interviewing the caregivers and secondly, by analysing their enterprise resource planning data, ultimately, providing an excellent additional source of quantitative empirical data for triangulation. The impact evaluations were first done through making a data sample request, analysing the data, facilitating a meeting with the customer organisation to discuss the results and sharing the final report with both the customer and the technology provider. This process was replicated with other home-care organisations to provide additional triangulation through the cyclical data collection enabled by the longitudinal case study (Eden \& Huxham, 1996). These replications also enabled the researchers to adjust their interventions and further pursue new theoretical insights as well as better joint benefits between the supplier and its customers.

Later the researchers identified that the organisation-level impact had to depend on the end customer selection, and together with the technology provider, they decided to increase their collaboration with the home-care organisations. The researchers were trying to help the home-care organisations identify best-case end customers, with whom the robot dispensers would have a significant impact, that would be more apparent also on the organisation-level. The home-care organisations, in return, provided data samples and insights from the home-care processes to support our research agenda. This collaboration enabled us to get closer to the customer organisations, expanding our access in the emic domain. Figure 3 shows the research process with different home-care organisations. Active collaboration has continued with the technology provider throughout the whole time.

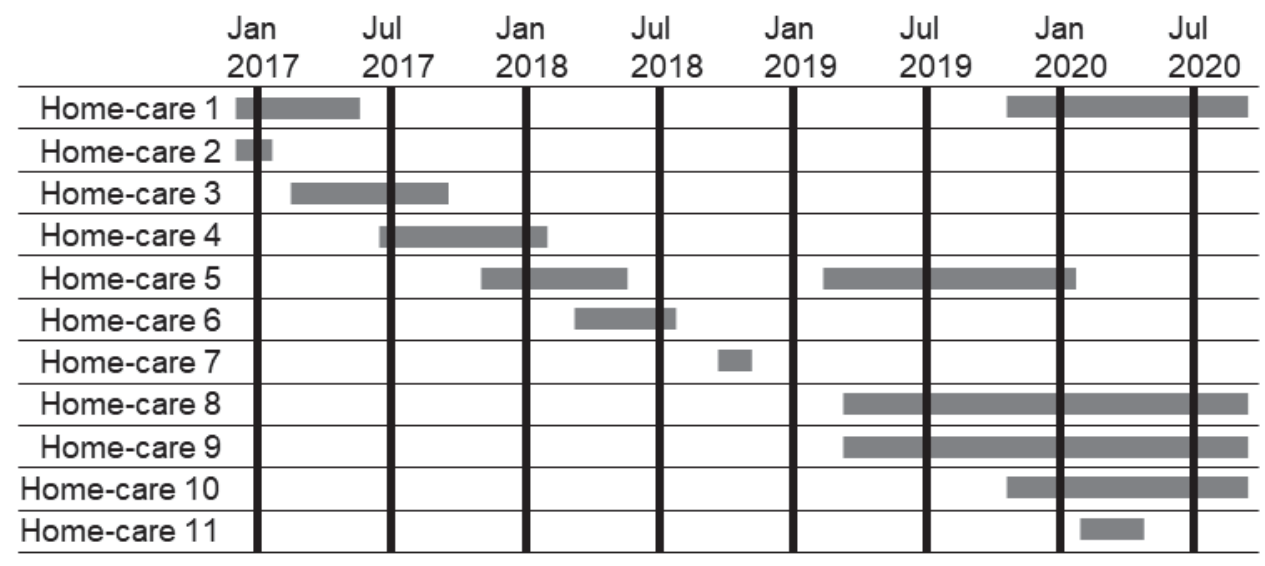

Figure 3: Timeline of the research process

We wanted to position ourselves in the middle of the supplier-customer dyad, co-creating the analytical models for evaluating the impact of the robot dispensers together with both the supplier and the customer. This way we could get in-depth empirical data on the impact evaluation from an accounting approach, as well as the related decision-making, with great contribution potential in management accounting (Scapens, 2004; Wouters \& Kirchberger, 2015), decision-making (Hall, 2010) as well as marketing literature (Grönroos, 2008; Wouters \& Kirchberger, 2015). However, since our case drove us towards the management of operations in home-care, we also identified new theory contribution potential in operations management and home-care literature.

This interventionist approach has given us access to several sources with both qualitative and quantitative data, illustrated in Table 1. Moreover, the observed events are not artificially created to discuss simulated cases, but the actual meetings where the robot dispenser implementations are discussed. The reports provided to homecare organisations and the technology provider are the actual reports being used for procurement decisions by the customers and marketing material by the technology provider. 
Table 1: Data gathering events with different home-care organisations

\begin{tabular}{|c|c|c|c|c|c|c|c|c|c|}
\hline Customers & 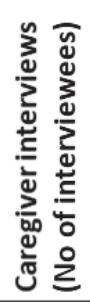 & 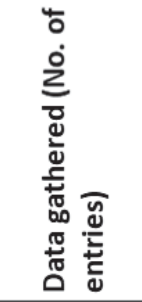 & 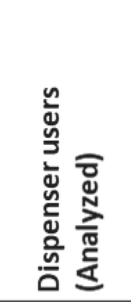 & 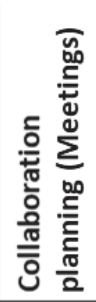 & 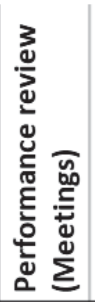 & 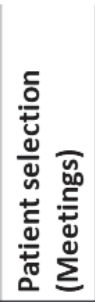 & 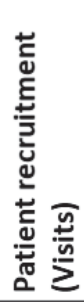 & 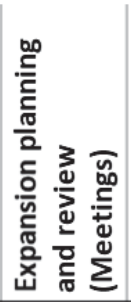 & 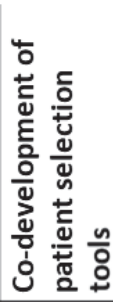 \\
\hline Home-care 1 & & 5842928 & 424 & 2 & 2 & & & 2 & $x$ \\
\hline Home-care 2 & 3 & & (14) & & & & & & \\
\hline Home-care 3 & 2 & 916 & 10 & 2 & 2 & 1 & 8 & & \\
\hline Home-care 4 & & 301 & 5 & 2 & 1 & & & & \\
\hline Home-care 5 & & 287091 & 22 & 3 & 3 & 2 & 8 & 8 & $x$ \\
\hline Home-care 6 & & 6158 & 21 & 1 & 1 & & & & \\
\hline Home-care 7 & & 257359 & 32 & 1 & 1 & & & & \\
\hline Home-care 8 & & 133459 & 11 & 5 & 1 & 10 & & & $x$ \\
\hline Home-care 9 & 1 & & (70) & 7 & & & & & \\
\hline Home-care 10 & & 1185624 & 216 & 2 & 2 & & & & \\
\hline Home-care 11 & & & & 1 & & & & & \\
\hline Total & 6 & 7323610 & (741) 825 & 26 & 13 & 13 & 16 & 10 & \\
\hline
\end{tabular}

During the longitudinal case was gathered through 6 interviews, 62 meetings, and 16 visits to end customers (patients). The 62 meetings include topics such as presenting research results from other home-care organisations, planning research collaboration, planning technology implementation, choosing end customers, observing end customer recruitment, reviewing performance and discussing future expansion plans. Additionally, the data is supplemented with experiences from more than 35 supplier meetings, as well as hundreds of calls and over 1,000 emails regarding the case made with different parties. The researchers have also been invited to give dozens of public talks of the importance of planning in technology implementations. Overall, the research data includes research notes from the meetings, research diary and audio recordings from some events as well as 7.3 Million records of home-care visits of 741 dispenser users (84 dispenser users analysed without records of visits) and 14,612 other home-care patients as samples gathered from these organisations as supplementary quantitative data.

\section{Empirical findings}

\subsection{Gaining access to the technology provider}

When the research collaboration started, the researchers were asked by the technology supplier to evaluate and document the financial implications for municipalities implementing the robot in their home-care organisations. The collaboration was strongly initiated with the supplier, who was also responsible for inquiring which potential customer would like to participate in a research collaboration. The research collaboration was openly received since home-care organisations were under pressure to reduce costs. Moreover, municipalities seldom had the resources for analysing the cost implications of new technologies and help from a neutral, third party, was welcomed by both parties.

"We need to show the municipality that the robots have saved costs if we want to keep them." (Director
of elderly care)

"They [The federation of municipalities 2] have put the implementation [expansion] on hold until we get the results from the performance analytics. It would be important to get the results as soon as possible." (Sales Director, Technology provider)

At first, the researchers were conducting interviews, creating simple value potential calculators and investigating individual patient cases. The value proposition seemed robust; if the robot reduced enough home-care visits each month, the cost savings would cover for its monthly fee. To validate the value proposition, the supplier wanted the researchers to document the change in home-care visits and analyse the cost savings enabled by robots. In addition, the supplier was interested in identifying the best end customers with whom the robot 
'brought most value'. The project started with interviews with the caregivers of Home-care 1 to get the caregivers' perspective on the perceived value, identify end customer profiles and gather information about the change enabled by the robots. With this information, the customer would be better able to identify end customers, and for the supplier, the results would also make an excellent reference case.

At the same time Home-care 2 had gathered data from their ERP-system, which allowed researchers to investigate the change in monthly visits based on actual numbers, providing excellent triangulation. After analysing the data, the researchers organised a meeting with the representative of Home-care 2 to discuss the findings. This became a standard process of future customer research collaboration since the presentation of the data stimulated interesting discussion providing rich research data and deepened access to the customer.

\subsection{Expanding access to one of the customers}

The major step in expanding access to the customer happened with the Home-care 3 and later with Home-care 5. The second customer case also indicated that the results were highly dependent on customer selection, which was pursued further in customer cases Home-care 3 and Home-care 5. This required a deeper collaboration than before, also enabling deeper access. The researchers also had gained experience and understanding about the technology, the home-care context and the financial implications, transforming them from outsiders to experts that could contribute to the discussions about customer selection. However, the researchers had to prove their place in the table.

"There is one thing I do not understand. How can you [as a researcher] choose our end customers? You do not know anything about them." (Head of services for elderly and disabled)

"That is not even something I would want to do. Your caregivers know the customers, and they are the best people to make the decision if the service works with a customer or if not. However, what I can do is provide you insights into the objectives, identified best customer profiles and possible effects than can be acquired with the service to help caregivers to choose the end customers. " (Researcher)

The researchers were invited to join caregivers when they visit the customers to understand more about the nature of the visits. These visits also enabled more informal discussions on the technology and home-care, arising some of the concerns the caregivers had, mostly related to identifying potential end customers and 'selling' the service to them. Thus, access started to get deeper, which was also suggested by Home-care 5's active requests for collaboration. However, in some supplier-customer dyads, the researcher was not able to gain similar access because while municipalities were interested in acquiring the performance analytics documents, gaining access to data that would be beneficial for academic purposes was sometimes more difficult than expected.

" Can you please prepare a new research plan and application that are [just] based on collecting [and analysing] the home-care visit records? [Healthcare federation] is also interested in acquiring this research result and we want it once it is done." (Development coordinator of social services)

\subsection{Resolving conflict as an intermediate between the supplier and customer}

Overall, it was rather easy to mediate between the supplier and the customer, since the home-care organisations were mostly happy with the robotic dispensers. However, the municipalities funding the robot dispensers wanted to see clear cost reductions, creating pressure for the home-care organisation, the technology provider and the researchers to identify ways to accurately measure the cost impact. This was not always straight forward, since many of the medicine adherence related benefits were indirect; higher adherence should improve or maintain the health of the patient longer, reducing the chances of hospitalisation or the need for an increased workload. Luckily there were significant operational impacts with some patients, but the difficulty was to identify enough of these best-case end customers. As such, the role of the researchers was to try to help achieve sufficient cost impact, measure it, and communicate the results to the different parties.

In addition, there was sometimes minor conflict within the individual meetings. For example, the researchers often were invited to or facilitated meetings with the home-care organisations, where the technology provider was also present. For example, occasionally, the researcher was confused as a representative of the supplier. In these cases, the researcher tried to always clarify their roles, and the confusions did not seem to impact the collaboration with, at least, the contact persons of these organisations.

"Today we have a few people here from [the supplier]. [After a short introduction to the topic of our visit, she asked] Could you please briefly introduce yourselves?" (Home-care manager) 
"I am [Researcher], and I'm actually from the university. We are working together with [the supplier] to investigate the impacts of the robot especially from the cost perspective." (Researcher)

The implementation was not always accessible within the larger home-care federations. Sometimes the customers did, for example, identify change resistance between the units or with single caregivers.

"In some units, they are able to identify several potential patients [end customers], and in other units, they claim not to have even a single potential patient, even though the patients are quite similar. Something must be going on." (Director of elderly care)

The home-care managers sometimes wanted to use the researcher to convince care units and caregivers to be open towards the solutions. The resistance to change was apparent, especially illustrated by a conversation the researcher had to have before a visit to a home-care unit that had been quite resistant to implementing any kind of technologies into their operations.

"They [Some home-care teams] have been against the implementation from the start, so I am not that optimistic about [the end customer selection in] these home-care teams. Let's see if they even let us in." (Caregiver responsible for the technology implementation)

"Should I bring the research permit with me?" (Researcher)

"[Laughing] That might not actually be a bad idea." (Caregiver responsible for the technology implementation)

Both parties used the position of the researcher as a neutral third party to their advantage when the source of information was important due to trust issues. As such, a little intervention, such as passive participant observation or commenting on the discussion, had an impact on the case context.

"It is completely different when a researcher says it, even if the numbers are the same." (Home-care manager)

"Just having you [the researcher] with me [in the end customer selection session] forces them to think and not come up with an excuse" (Caregiver responsible for the technology implementation)

"It is really efficient to be able to show previous customer case reports that were not done by us, but by a neutral, third-party researcher." (Sales director, the technology provider)

The cost information sometimes put the researcher between conflicting interests. The salespeople of the technology provider would like a simple price tag for a home-care visit. The home-care organisations would have wanted to know the bottom line on if the technology has saved enough money or not. However, the researcher was acting on complex effects with limited information, which is why it was hard to provide anything concrete. The researcher preferred trying to increase the accounting understanding of both parties instead of giving ammunitions that the parties could cite the researcher for, forcing the researcher to 'take a side'. In addition, the customers often asked the researcher for the price of the service, which varied between contracts and could have hurt the supplier if shared. Hence, the researcher always requested information about the service fee from the customer or used a pre-agreed estimate to avoid unnecessary conflict.

The interventions and active participation with both the supplier and customer have helped the researcher gain access to both organisations. The researcher discussed sensitive information, even about the contacts' relationships inside and between the supplier and the customer. This suggests that the researcher was able to gain access as 'one of us' in both organisations in some of the supplier-customer dyads. Importantly, the researcher's role evolved to this position partially as an objective and partially unknowingly. It was not before the researchers reflected on the role that the possible complications of the role were acknowledged, which is why the positioning is worth some discussion.

\section{Discussion}

\subsection{The taxonomy of the three positions}

During the research process, the nature of the researcher's role evolved; the researcher first started by getting access to the technology provider and then moved closer to working together with the customers. First, the 
researcher moved from the etic domain to the emic domain with one of the organisations (technology provider), as typical for most interventionist studies (Suomala et al., 2014; Laine et al., 2018). The active collaboration on assessing the customer value and co-developing customer value propositions deepened access to the supplier. When the research collaboration was expanded towards the customer organisation, and more specifically, municipalities 3 and 4 , the researcher was starting to gain access to the other, customer, organisation as well. Here, especially the cooperation with improving end customer selection, and the provided performance analytics were in key roles for getting access to the customer organisations. However, once conflicts started to arise, the importance of positioning within the supplier-customer dimension started to become important.

Not only did the researcher move between the etic and emic domains (Jönsson \& Lukka, 2007), but he also moved within the supplier-customer dyad. Because of this possibility, the etic and emic perspectives are insufficient to represent the variety of possible position an interventionist researcher can assume in the interorganizational supplier-customer dyads. Within the supplier-customer dimension illustrated in Figure 2, the researcher can navigate between the insider roles of either of the opposites, the supplier or the customer, or somewhere in-between. Thus, while the positioning happens in a two-dimensional continuum, we can significantly differentiate three main positions. Following the idea of 'one of us' by Jönsson and Lukka (2007) and the varying levels of in-depth access (Suomala \& Lyly-Yrjänäinen, 2011), this paper proposes three positions that the interventionist researcher can take in an interorganizational supplier-customer dyad: an auditor, a lawyer or a mediator. The positions are illustrated in Figure 4.
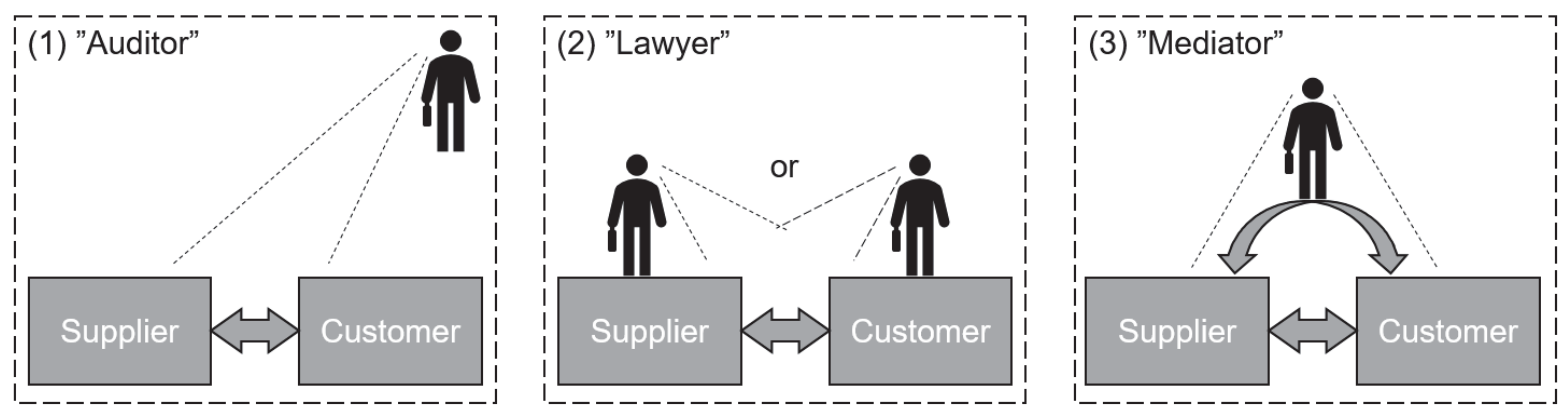

Figure 4: Interventionist researcher's three positions in a supplier-customer dyad

The auditor investigates the interface between the supplier and the customer as an outsider. As such, the researcher actively remains as a third, neutral party, keeping away from taking either side. The lawyer position compromises this perceived neutrality (but not independence) for deeper access to empirical data regarding one of the organisations. Thus, the lawyer actively pursues the status of 'one of us' with either the supplier or the customer. The mediator expands the previous positions by trying to achieve a status of 'one of us' in both organisations trying to understand both sides of the same story supporting both the supplier's and customers' activities. Hence, she requires the ability to navigate between the sometimes-conflicting interests of both parties, resulting in a more complex 'battlefield' than before (Suomala et al., 2014). In the case, the researcher started as an auditor and first pursued access with the supplier, moving towards the lawyer position. Later during the case, the researcher expanded his access towards the customer, moving closer to the mediator position.

The problem with the classification of an insider and an outsider rises in the supplier-customer dyad. Typically, the researcher navigates between the emic and etic perspectives (Jönsson \& Lukka, 2007). In a supplier-customer dyad, tensions and conflicting interests between the organisations and the insider status does not necessarily expand over the whole dyad. Moreover, investigating one organisation as a lawyer of the other does not imply that the researcher takes an etic perspective since etic and emic refer to looking at practice from either inside the practice (emic) or outside the practice (etic) (Jönsson \& Lukka, 2007). While the auditor position remains in the etic perspective, the lawyer and mediator positions are different positions within the emic perspective, as illustrated by Figure 5 . 


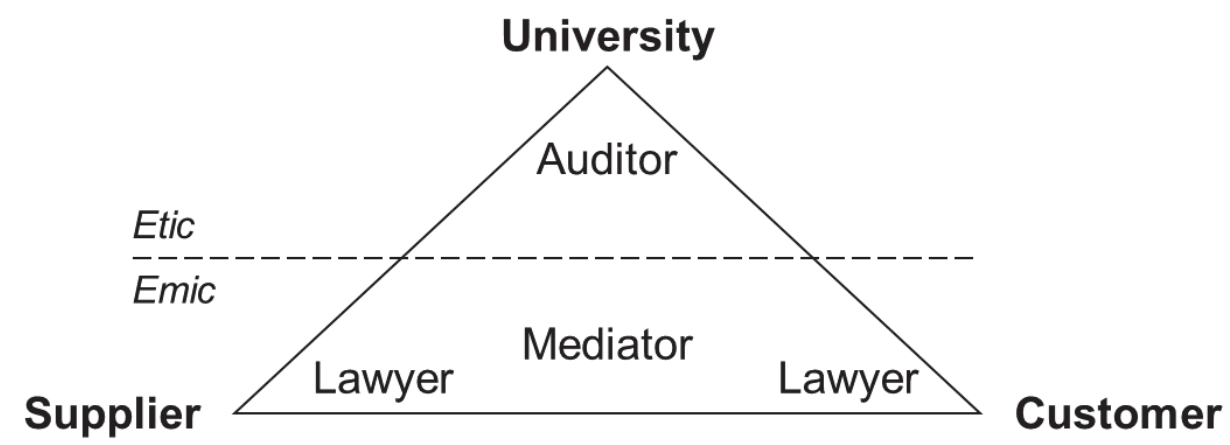

Figure 5: The three positions within the expanded etic and emic domain

While interventionist research includes the navigation between the etic and emic perspectives (Jönsson \& Lukka, 2007), the position does not change every time the researcher takes the etic perspective. For example, when the researcher was concurrently working on research publications, he did not suddenly lose his status as 'one of us' at the technology provider or the customers, though the mediator position might have weakened due to the time taken away from the field work. Moreover, when the researcher changes their position, she keeps part of the mindset she had in the previous position. When the researcher started deeper collaboration with the customer side, he still had a supplier-dominant perspective, analysing how the home-care should change their operations with the technology to gain the expected benefits. However, after more and more time was spent at the customers, he also started recognizing issues from the supplier side; there were many possibilities how the supplier could improve and better serve their customers, for example, by supporting the end customer selection.

The transition between the positions is slow, especially when trying to return from a mediator to an auditor. This is due to the researcher having already been 'corrupted' by the mindset taken while working with either party. In the case, the researcher was naturally drawn to the supplier's lawyer position, which made it more difficult for him to later adopt a customer-perspective. Therefore, the researcher would benefit from remaining as an auditor until she has planned her positioning as part of the research design. As McSweeney (2004) suggests when discussing critical independence, "But for action-research, where the outcome might have adverse or uneven consequences for diverse organisational parties, I suggest that in the initial exploratory stage relations are best kept formal." Choosing and acquiring a position will affect access to data as well as the mindset that the researcher takes, and thus, will affect the research results or at least the theoretical framing of the results. Choosing a side does not mean that the researcher should lose their independence (MacSweeney, 2004), and taking advantage of the neutrality of representing a third party, a university, would be highly unethical. However, choosing a side can help the researcher manage the interventions in a way that positions her favourably from the research domain's perspective, manage the workload required to gain the access she wants, and avoid any unnecessary conflicts that could jeopardise her status.

\subsection{Possibilities and limitations of the three positions}

There is no single best pick among the three positions, but instead, each position comes with its own possibilities and limitations. First, the workload required to achieve a position may significantly vary between the three positions. In the case, the researcher had been actively working for several months before gaining access to observe the home-care operations with Home-care 3 and almost a year before starting the active collaboration with Home-care 5. The access to the technology provider (the supplier) has also evolved over time and new insights are still gathered even after several years or collaboration. Second, the lawyer position made it difficult for the researcher to view issues from the customer perspective, thus, compromising the neutrality of the researcher. Furthermore, while the mediator position could be pursued to regain a wider perspective on the supplier-customer interface, it also put the researcher more prone to face conflicting interests, related to pricing for example. However, the strength of the lawyer and mediator positions come from the in-depth access to rich data. Even after several years of collaboration with both parties, the researchers are still gaining new empirical insights and pursuing new research agenda in collaboration with both the supplier and the customers. Figure 6 roughly illustrates the access to data based on the empirical findings of the longitudinal case. 

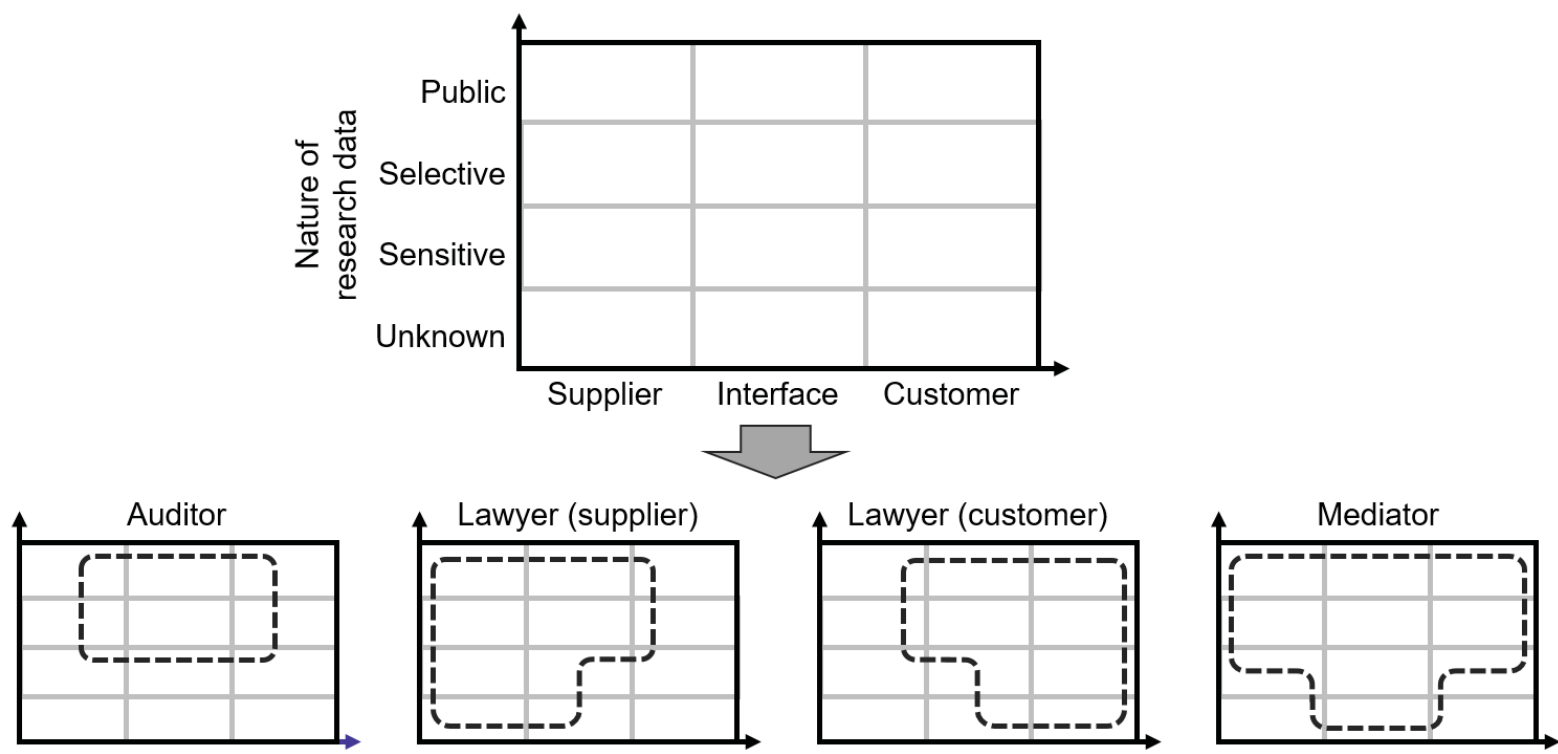

Figure 6: The three positions and access to research data and results

The auditor position was the starting position for the researcher before getting access to the supplier organisation. In some interventionist studies about open-book accounting, suppliers have shared some cost information with their customers, seeking win-win situations (Kulmala et al., 2000). The intervening researchers have also positioned themselves as neutral, third party, providing cost analytics free of hidden agenda (Kulmala et al., 2000). In this position, it can be more challenging to gain access to sensitive or unknown information, limiting the depth of access to the first three levels by Suomala and Lyly-Yrjänäinen (2011) and focusing on the domain of the interface between the supplier and the customer. In the case, the researcher started by making simple cost calculations to elaborate on the cost implications of the technology. However, at this point the researcher did not yet have any hard evidence on the actual operational implications of the technology. The key feature of this position is that the researcher remains in the etic perspective and does not become an insider in either organisation. Additionally, in this position, it is easier to remain formal and keep away from conflicting interests that could jeopardise the researcher's critical independence (McSweeney, 2004). However, these benefits come with limited access to the rich data interventionist research is known for.

As a lawyer, the researcher chooses a perspective for their research and party with whom they try to gain deeper access. This is especially important when the intervention is more than access (Suomala \& Lyly-Yrjänäinen, 2011). In the case, the researcher started working together with the supplier to document the actual operational implications of the technology to develop the value propositions of the company, in-line with his original research agenda. In some previous studies, the intensive work performed together with the supplier often has positioned the researcher as 'one of us' in the supplier's management team and, to maintain the trust, the researchers have been rather cautious what information to share to the customer (Suomala et al., 2010). Similar sensitivity was required in the case study, for example, regarding the price and cost information. However, having collaboration with the party, the researcher can gain deeper access to one of the organisations up to the deepest level, native role, discussed by Suomala and Lyly-Yrjänäinen (2011). Otherwise, if access remains lower than level three, the position remains more likely as an auditor.

A mediator is considered 'one of us' with both the supplier and the customer, which might help the researcher understand the big picture. In the case, the researcher identified the importance of patient selection in enabling the operational implications, and thus, the cost benefits. However, this required more in-depth understanding about the home-care processes, and pushed the researcher to pursue a 'one of us' role in the customer organisation as well. Thus, researcher might have to jump between being an insider in one organisation to another and, hence, she requires the ability to navigate between the sometimes-conflicting interests of both parties, resulting in a more complex 'battlefield' than before (Suomala et al., 2014). However, the researcher will keep part of the other organisation's perspective, which might limit her from achieving the deepest level of access by Suomala and Lyly-Yrjänäinen (2011). On the other hand, the mediator might become the best expert around the interface between the organisations, which makes it beneficial for both parties to collaborate with the researcher and could give the researcher power to coordinate research effort. It should be noted though 
that becoming a mediator should not mean becoming a double agent. There is the risk, though, that the parties would like the mediator to share sensitive information. In the case, the researcher asked the customer's representatives the permission to share results with the supplier and vice versa. In this case, these requests to share information were received positively, since it was mutually beneficial to 'open the books'. In other cases, the researcher might need to disclose why the other party would be interested in this data, primarily if the researcher identifies a chance of conflict.

\subsection{Guidelines for positioning for interorganizational interventionist researchers}

The guidelines and implications of this paper (in practice) are essentially those of the research in practice. They thus apply to the interventionist researchers engaged in interventionist research projects. Indeed, the advantage and a potential pitfall of interventionist research is the access to the organisational settings with different stakeholders, parties, values and power structures. Therefore, the interventionist researcher needs to firstly understand the difficulty of being utterly neutral while in the "battlefield" (Suomala et al., 2014) of organisational practice. Thus, based on the paper, the interventionist researcher needs to be aware of the existence of different positions and her actual position to the subject of interventionist study.

Second, as practical implications, the paper provides the taxonomy to support the positioning of the interventionist researcher. The roles of auditor, mediator and lawyer were identified and proposed in order to unveil the possibly unique roles of an interventionist researcher, especially in interorganizational interventionist research projects. However, the taxonomy may be helpful to other interventionist researchers. This is, in part, due to that fact that larger organisations may possess functional boundaries or business unit boundaries at the interface where an interventionist researcher needs to operate. One example of the different roles of the interventionist researcher within an organisation was discussed by Laine et al. (2016). As an interventionist researcher, "boundary subject" was both auditor and mediator in the organisation.

Third, the interventionist researcher may choose her role, or the role may be a result of an evolutionary process. The role is 'given' by the people the interventionist researcher interacts with and, thus, not something the researcher can completely decide by herself. However, the interventionist researcher can pursue a specific role that fits her research agenda and design. In any case, the researcher needs to be honest and transparent regarding the selected role or the possibility of an evolving role. The researcher cannot "play any role", but more readily be aware of and reflect upon the practice and her role in the interventionist research process. Moreover, the positioning is not only something that should be considered before the research project, but indeed, reflection is beneficial during and especially after the research project. In some cases, the researcher might not be completely aware of her own position before distancing herself from the research project or reflecting on the position with colleagues.

\section{Conclusion}

The paper introduces an issue regarding the emic perspective that has not received enough attention in prior literature: can and should the interventionist researcher become an insider in two organisations simultaneously? Since becoming 'one of us' in one organisation might result in becoming 'one of them' in the other, the researcher will have to decide how to position herself. In response to our first research question, our empirical findings suggest that the interorganizational interventionist researcher can navigate between three positions: an auditor, a lawyer, and a mediator. First, the interventionist researcher can assume an auditor position, keeping their distance from the dyad and researching the setting from the etic level. In the auditor position, the researcher can best avoid confliction and manage workload, but is restricted in access to data. Second, the researcher can try to gain access to either the supplier or the customer as a lawyer, which can provide an access to rich data regarding sales and sourcing domains but can require more work and compromise the neutral position of the researcher. Third, the researcher can assume a mediator role, in which she gains access as 'one of us' in both organisations. In this position, the researcher will have to work hard to maintain her position as 'one of us' in both organisations, having to navigate between conflicting interests to gain access to rich empirical data. Thus, as a response to our second research question, each position has its own possibilities and limitations regarding how the researcher can manage conflicting interests, balance her workload and gain access to information relevant to her research design. The taxonomy presented in this paper helps the interventionist researcher choose a suitable position for her research design and helps to avoid potential methodological pitfalls arising from such a novel setting. 
Since this paper discusses a novel setting for doing research, interventionist research on several domains around customer value are highly welcomed. From a methodology point of view, this paper proposes the framework of three positions but elaborates mostly on the transition from lawyer to mediator positions. Moreover, teamwork between researchers and positions in multi-position research collaboration is worth investigation. A full review of these three positions would also require the auditor position and customer's lawyer position, left mostly unexplored in this paper. Additionally, the case is conducted within a business-to-government setting, with demand for the facilitation of value co-creation, but with some limitations regarding transferability, especially in a business-to-business setting. Thus, a natural future step would be to validate the taxonomy in a businessto-business setting. Finally, the paper explores the role of the interventionist researcher as a facilitator of value co-creation. However, this role either as a value co-creator or as a facilitator of value co-creation, especially related to the temporality of the intervention, would benefit from further investigation.

\section{Acknowledgements}

The NewBI5 research project resulting in this paper was funded by Business Finland and companies. The authors wish to thank the representatives of the supplier organisation and the home-care customers for access to novel settings with an incredibly rich dataset. The authors also want to thank the participants of the 'Qualitative research in management accounting: developing the interventionist research (IVR) approach' seminar at Tampere University 12/2019 for their helpful comments that gave the inspiration for this paper. The authors also want to thank the support from participants of the '19th European Conference on Research Methodology for Business and Management Studies' at Madeira, Italy 6/2020, where an earlier paper was presented under the title: 'Interventionist Researcher Facilitating Value Co-Creation: 'One of us' or 'one of Them". Finally, the authors want to thank the anonymous reviewers and the editors for their excellent comments and feedback during the development of the paper.

\section{References}

Caglio, A. and Ditillo, A., 2008. Review and discussion of management control in inter-firm relationships: Achievements and future directions. Accounting, Organizations and Society, 33, pp 865-898.

Chandrasekaran, A., de Treville, S. and Browning, T., 2020. Editorial: Intervention-based research (IBR)-What, where, and how to use it in operations management. Journal of Operations Management, 66(4), pp 370-378.

Eden, C. and Huxham, C., 1996. Action Research for Management Research. British Journal of Management, 7, pp 75-86.

Ellström, D. and Hoshi, L.M., 2017. Dynamic and static pricing in open-book accounting", Qualitative Research in Accounting and Management, 14(1), pp 21-37.

Grönroos, C., 2008. Service logic revisited: who creates value? And who co-creates? European Business Review, 20(4), pp 298-314.

Jakobsen, M., 2013. Inter-organizational cost management. In F. Mitchell, H. Nørreklit, and M. Jakobsen, ed. 2003. The Routledge Companion to Cost Management. Oxon: Routledge. pp 215-228.

Jönsson, S. and Lukka, K., 2007. There and Back Again: Doing Interventionist Research in Management Accounting. Handbooks of Management Accounting Research, 1, pp 373-397.

Kajüter, P. and Kulmala, H.I., 2005. Open-book accounting in networks: Potential achievements and reasons for failures. Management Accounting Research, 16(2), pp 179-204.

Kulmala, H., Happonen, M-P., Lahikainen, T. and Paranko, J., 2000. Win-Win in Action - a Case Study. In: Proceedings of the 2000 IEEE International Conference on Management of Innovation and Technology - ICMIT 2000, 'Management in the 21st Century', 2000 IEEE International Conference on Management of Innovation and Technology - ICMIT 2000. Singapore, 12-15 Nov. 2000. Singapore: IEEE.

Laine, T., Korhonen, T., Suomala, P. and Rantamaa, A., 2016. Boundary subjects and boundary objects in accounting fact construction and communication. Qualitative Research in Accounting \& Management, 13(3), pp 303-329.

Laine, T., Lyly-Yrjänäinen, J., Korhonen, T. and Suomala, P., 2018. Interactions enhancing the impact of the interventionist research: Case service business development. In: ECRM 2018 17th European Conference on Research Methods in Business and Management, European Conference on Research Methodology for Business and Management Studies, Rome, 12-13 Jul. 2018. Italy: Academic Conferences and Publishing International.

Lyly-Yrjänäinen, J., Suomala, P., Laine, T. and Mitchell, F. 2017. Interventionist management accounting research: theory contributions with societal impact. New York: Routledge, $192 \mathrm{p}$

Munro, R., 1996. Alignment and identity work: the study of accounts and accountability. In: R. Munro \& J. Mouritsen, ed. 1996. Accountability - Power, Ethos \& the Technologies of Managing. London: Thomson. pp 1-20.

McSweeney, B., 2004. Critical Independence. In: C. Humphrey, and L. Bill, eds. The Real Life Guide to Accounting Research: A Behind-the-Scenes View of Using Qualitative Research Methods, Elsevier Science. pp 207-226.

Oliva, R., 2019. Intervention as a research strategy. Journal of Operations Management, 65(7), pp 710-724.

Rantanen, P., Parkkari, T., Leikola, S., Airaksinen, M. and Lyles, A., 2017. An In-home Advanced Robotic System to Manage Elderly Home-care Patients' Medications: A Pilot Safety and Usability Study. Clinical Therapeutics, 39(5), pp 10541061. 
Romano, P. and Formentini, M., 2012. Designing and implementing open book accounting in buyer-supplier dyads: A framework for supplier selection and motivation. International Journal of Production Economics, 137(1), pp 68-83. Saukkonen, N., Laine, T. and Suomala, P. 2018. Utilizing management accounting information for decision-making. Qualitative Research in Accounting \& Management, 15(2), pp 181-205.

Seal, W., Cullen, J., Dunlop, A., Berry, T. and Ahmed, M., 1999. Enacting a European supply chain: a case study on the role of management accounting. Management Accounting Research, 10, pp 303-322.

Scapens, R.W., 2014. My final editorial. Management Accounting Research, 4(25), pp 245-250.

Stormi, K., Lindholm, A., Laine, T. and Korhonen, T., 2020. RFM customer analysis for product-oriented services and service business development: an interventionist case study of two machinery manufacturers. Journal of Management \& Governance, 42(3), pp 623-653.

Suomala, P., Lahikainen, T., Lyly-Yrjänäinen, J. and Paranko, J., 2010. Open book accounting in practice - exploring the faces of openness. Qualitative Research in Accounting and Management, 7(1), pp 71-96.

Suomala, P. and Lyly-Yrjänäinen, J., 2011. Management Accounting Research in Practice. New York: Routledge, $140 \mathrm{p}$ Suomala, P., Lyly-Yrjänäinen, J. and Lukka, K., 2014. Battlefield around interventions: A reflective analysis of conducting interventionist research in management accounting. Management Accounting Research, 25, pp 304-314.

Wouters, M. and Kirchberger, M.A., 2015. Customer value propositions as interorganizational management accounting to support customer collaboration. Industrial Marketing Management, 46, pp 54-67. 